\section{Overtube-assisted over-the-wire stent placement to treat a post-surgical duodenal leak}

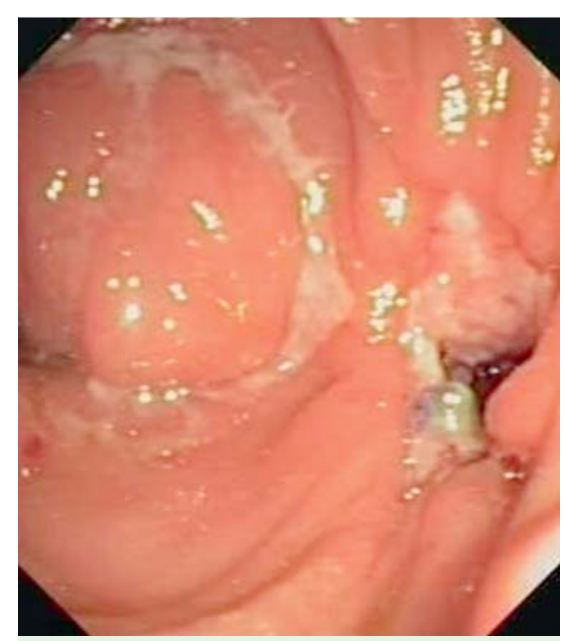

Fig. 1 Post-surgical duodenal leak following right hemicolectomy because of distal ileum abscess in a 51-year-old woman with Crohn's disease.
A 51-year-old woman affected with Crohn's disease developed a distal ileum abscess requiring right hemicolectomy. A few days later, bile was flowing from surgical drains, and a computed tomography (CT) scan showed a duodenal leak. Surgical suture of the duodenal wall was attempted, but failed.

The patient was then referred to our institute and, to promote duodenal healing, the predetermined goal was to stop both the enteric and the biliary flows through the leak ( Fig.1). A percutaneous transhepatic cholangiography (PTC) was done to divert bile flow. To divert the enteric flow, a treatment with a fully covered metal stent ( $26 \mathrm{~mm}$ body diameter, $34 \mathrm{~mm}$ flare diameter, and $10 \mathrm{~cm}$ length; Beta stent; Taewoong Medical, Gyeonggi-do, South Korea) ( Fig. 2) was planned. The Beta stent is an over-the-wire stent, with a specific antimigration system, developed for the treatment of post-bariatric surgery leak. To enhance the depth of the stent insertion into the duodenum, a single-balloon enteroscopy overtube (ST-SB1; Olympus Europe, Hamburg, Germany) was used to prevent gastric looping thus straightening the release system from the esophagus through the stomach to the distal duodenum [1]. The procedure was carried out under endoscopic and radiologic control and with the patient under general anesthesia. The enteroscopy overtube was advanced through the duodenum and stabilized beyond the ligament of Treitz. A small orifice was created by puncturing the overtube about $70 \mathrm{~cm}$ from its distal end ( $\bullet$ Fig. $3 a$ ) and the Beta stent was inserted through the orifice over the wire ( Fig.3b). When the stent was in the correct position, the overtube was twisted and slightly retracted allowing stent placement from the duodenal bulb beyond the ligament of Treitz ( Video 1 ). The abdominal drainage flow stopped immediately, and the patient was restarted on oral feeding 1 week later. The stent was removed 3 months later, and the leak
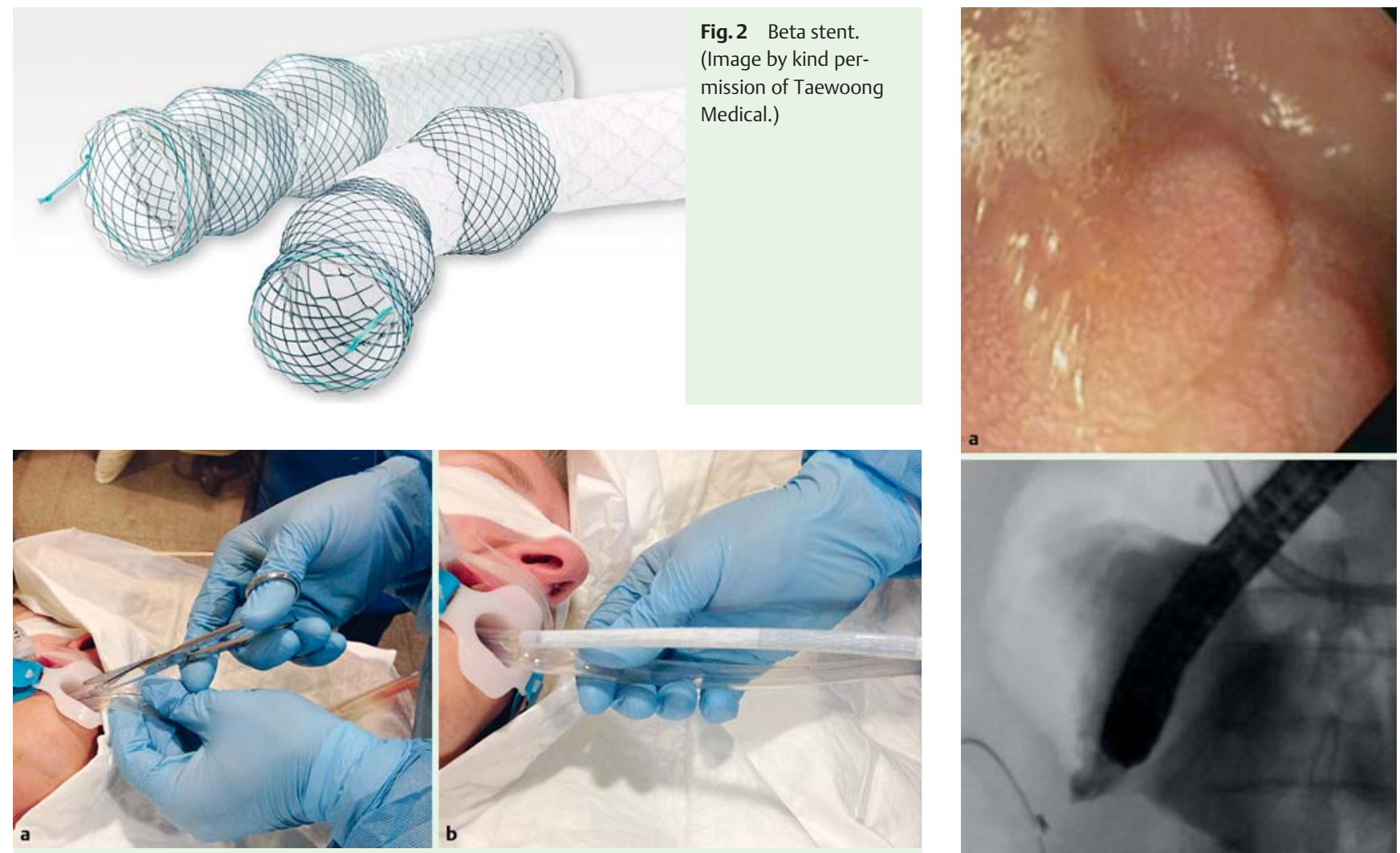

Fig.3 An overtube was advanced to the distal duodenum, to assist placement of the large-bore stent. a Small orifice created by puncturing the overtube. b Over-the-wire stent insertion through the orifice.
Fig. 2 Beta stent. (Image by kind permission of Taewoong Medical.)

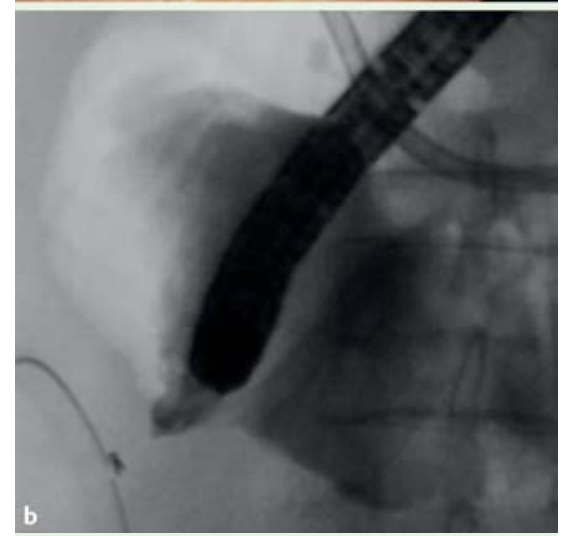

Fig. 4 Site of the resolved duodenal leak. 


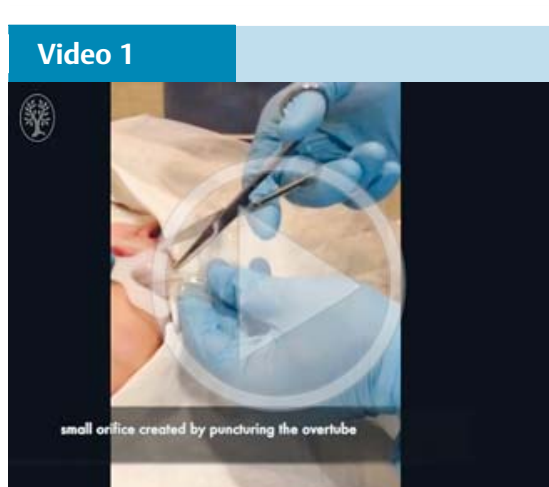

Post-surgical duodenal leak treated by overtube-assisted over-the-wire stent placement.

appeared to have resolved ( $\bullet$ Video 1 , - Fig.4). The patient remained asymptomatic during the 8-month follow-up.

Duodenal leak is a life-threatening condition, with a high rate of complications, and entailing a long period of hospitalization. Diversion of the enteric and the bili- ary flows away from the fistula seems to be effective in promoting rapid healing [2]. This report describes a new, overtube-assisted method for safely releasing a large-bore over-the-wire enteral stent directly into the duodenum to resolve a case of leakage.

Endoscopy_UCTN_Code_TTT_1AP_2AD

\section{Competing interests: None}

\section{Antonino Granata ${ }^{1}$, Gabriele Curcio ${ }^{1}$, Dario Ligresti ${ }^{1}$, Ilaria Tarantino ${ }^{1}$, Luca Barresi $^{1}$, Gaspare Solina ${ }^{2}$, Mario Traina ${ }^{1}$}

${ }^{1}$ Endoscopy Service, Department of Diagnostic and Therapeutic Services, IRCCS-ISMETT (Istituto Mediterraneo per i Trapianti e Terapie ad alta specializzazione), Palermo, Italy

${ }^{2}$ U.O. Chirurgia Generale, A.O. Ospedali Riuniti Villa Sofia-Cervello, Palermo, Italy

\section{References}

1 Tierney WM, Adler DG, Conway JD et al. Overtube use in gastrointestinal endoscopy. Gastrointest Endosc 2009; 70: 828 - 834

2 Cozzaglio L, Coladonato M, Biffi R et al. Duodenal fistula after elective gastrectomy for malignant disease: an Italian retrospective multicenter study. J Gastrointest Surg 2010; 14: $805-811$

Bibliography

DOI http://dx.doi.org/

10.1055/s-0042-109266

Endoscopy 2016; 48: E220-E221

(c) Georg Thieme Verlag KG

Stuttgart · New York

ISSN 0013-726X

Corresponding author

Antonino Granata, MD

Endoscopy Service, IRCCS-ISMETT

Via Tricomi, 5

90127 Palermo

Italy

Fax: +39-091-2192400

agranata@ismett.edu 